\section{CONSTITUTIONAL VIRILISM*}

BY

DAVID FERRIMAN, D.M., M.R.C.P. Physician, North Middlesex Hospital

P. KYNASTON THOMAS, M.D., B.Sc. M.R.C.P.

Registrar, Middlesex Hospital

AND

\section{ANTHONY W. PURDIE, M.B., F.R.F.P.S.} F.R.C.O.G.

Obstetrician and Gynaecologist, North Middlesex Hospital

This paper springs from an attempt to assess the clinical significance of idiopathic hirsutism in women. The association between hirsuties and other masculine characteristics, and with disturbances of menstrual periodicity, has been investigated and the familial incidence of the condition studied.

As a necessary preliminary to the inquiry a survey on the variations in the degree of hair growth in women was undertaken. The results are to be reported elsewhere (Thomas and Ferriman, 1957). The lip, chin, and lower abdomen were chosen for study, and observations were made upon a consecutive series of 584 general medical and surgical patients unselected except in so far as patients with diseases, such as myxoedema, known to influence hair growth were excluded. It was found that there was no clear demarcation between hirsute and nonhirsute subjects, hirsuties existing as a graded phenomenon. A system of grading was therefore elaborated, five grades of terminal (coarse) hair growth being recognized at each site. Grade 0 was the absence of hair. There were two minor grades ( 1 and 2 ) and two major grades ( 3 and 4 ), the latter approximating to the popular conception of hirsuties. In the 15-44 age group a little over one-half showed a grading of 0 at all three sites, whereas an appreciable proportion-in the region of $10-15 \%$ - had a major degree of hirsuties at one or more sites. In the post-menopausal period the incidence of facial hirsuties increased greatly, whereas hair on the lower abdomen virtually disappeared.

\section{Hirsuties, Body Build, and 17-Ketosteroid Excretion}

It seemed of interest to determine whether any relationship existed between the degree of hair growth and other characteristics which show differences between the sexes. Shoulder and hip width and the 24-hour urinary excretion of 17-ketosteroids were chosen for study. A comparison has been made between results obtained for groups of "hirsute" and "non-hirsute" subjects.

Probably the most useful means of distinguishing between the skeletal measurements of males and females is a comparison between shoulder and hip widths (for example, Tanner, 1951 ; Lindegård, 1953 ; Škerlj, 1953), males having a greater shoulder width and females a greater hip width in relation to height.

Measurements of biacromial and bi-iliac width were made on 43 hirsute subjects and 101 non-hirsute subjects, all being within the 18-44 age range. Hirsute subjects were defined as individuals showing a major degree of hirsuties on the lip, chin, or lower abdomen; they were a selected group derived from various sources. A subgroup, comprising those in whom the onset of hirsuties was stated by

*The material contributed by one of us (P. K. T.) formed part of a thesis submitted for the degree of Doctor of Medicine of the University of London. the patient to have been during adolescence, was also utilized. The non-hirsute group consisted of a consecutively observed series taken from the survey reported by Thomas and Ferriman (1957) with zero or minor grades of hirsuties. The results obtained are shown in Table I, where the means

TABLE I.-Mean Biacromial and Bi-iliac Widths, in Centimetres. for Non-hirsute and Hirsute Subjects

\begin{tabular}{|c|c|c|c|}
\hline Group & $\begin{array}{c}\text { Biacromial } \\
\text { Width }\end{array}$ & $\begin{array}{l}\text { Bi-iliac } \\
\text { Width }\end{array}$ & $\begin{array}{l}\text { No. in } \\
\text { Group }\end{array}$ \\
\hline $\begin{array}{ll}\text { Non-hirsute } & \ldots \\
\text { Hirsute: } & \ldots \\
\text { All subjects } \\
\text { Onset during adölescence }\end{array}$ & $\begin{array}{l}36.63 \pm 1.60 \\
37 \cdot 71 \pm 1.95 \\
38.40 \pm 1.64\end{array}$ & $\begin{array}{l}29.04 \pm 1.74 \\
29 \cdot 19 \pm 1.63 \\
28.98 \pm 1.73\end{array}$ & $\begin{array}{r}101 \\
43 \\
24\end{array}$ \\
\hline
\end{tabular}

and standard deviations for the different groups are given The difference between the non-hirsute and all hirsute subjects is brought out clearly in Fig. 1.

Biacromial width is significantly greater in the hirsute as compared with the non-hirsute group employing the $t$ test $(t=6.66 ; P<0.001)$, and is particularly so for the hirsute subgroup with onset of hirsuties during adolescence $(t=$ 7.68). No significant difference between the groups with respect to bi-iliac width is detectable (b y analysis of variance). $\mathrm{This}$ latter finding indicates that the observed difference in shoulder width d o e s not depend upon differences in general body size.

Estimations of the 24-hour urinary excretion of 17 ketosteroids were obtained for 66 hirsute and 25 non-hirsute subjects. The hirsute group was similar to that just described; the nonhirsute group consisted of individuals with a grading of not greater than 1 at all three areas, the large majority having a grading of 0 at each site. The results ob$t a$ in ed are displayed in Fig. 2. The histogram demonstrates a striking difference between the $t w o$ groups. The mean value for the hirsute group was

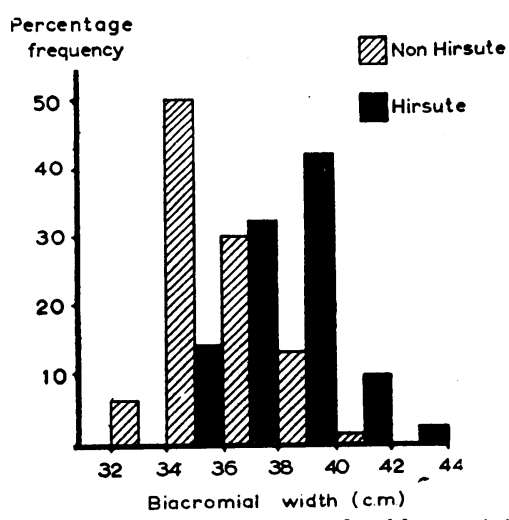

Fig. 1.-Distribution of biacromia widths for hirsute and non-hirsute subjects.

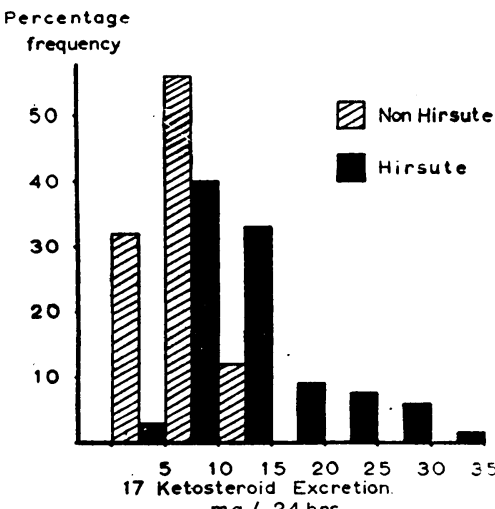
$\mathrm{mg} / 24 \mathrm{hrs}$

Fig. 2-Distribution of 24-hour urinary 17-ketosteroid excretions for hirsute anit non-hirsute subjects.
$13.02 \pm 6.6 \mathrm{mg} . / 24$ hours, the corresponding value for the non-hirsute subjects being $7.00 \pm 2.6$. It is of interest that this latter value is appreciably lower than that ordinarily found for the normal female 17-ketosteroid excretion, but it will be realized that it is derived from a specially selected group. The difference between the two is statistically significant $(\mathrm{t}=4.45 ; \mathrm{P}<0.001)$.

\section{Hirsuties and Menstrual Periodicity}

The association generally believed to exist between hirsuties and oligomenorrhoea was investigated during the course of the survey on hair growth in women to which 
reference has already been made. A menstrual history was taken in all 584 patients. For the purpose of this investigation it was decided to accept as oligomenorrhoea only the occurrence of cycles of at least five weeks and when this had been present for at least two years. Many patients were of course more severely affected than this. The change in hair distribution which takes place in later life precludes the consideration of decades above the age of 54. Patients whose lower abdomens had been shaved for abdominal operations before being examined were excluded. There remained 349 patients for analysis.

Table II shows the incidence of oligomenorrhoea in patients with a major degree of hirsuties on the lip, chin, or lower abdomen (hirsute) as compared with the incidence in the remainder (non-hirsute). It will be seen that 10 out of 53 hirsute patients as compared with only 13 out of

TABLE II.-Incidence of Oligomenorrhoea in Hirsute and Nonhirsute Subjects

\begin{tabular}{|c|c|c|c|c|c|c|}
\hline \multirow{2}{*}{\multicolumn{3}{|c|}{ Age Group }} & \multicolumn{2}{|c|}{ Non-hirsute } & \multicolumn{2}{|l|}{ Hirsute } \\
\hline & & & \multirow{2}{*}{$\begin{array}{c}\text { Oligomenorrhoea } \\
3 \\
3 \\
3 \\
4\end{array}$} & \multirow{2}{*}{$\begin{array}{c}\text { Total } \\
68 \\
64 \\
67 \\
97\end{array}$} & \multirow{2}{*}{$\begin{array}{c}\text { Oligomenorrhoea } \\
2 \\
4 \\
2 \\
2\end{array}$} & \multirow{2}{*}{$\begin{array}{c}\text { Tota } \\
14 \\
16 \\
11 \\
12\end{array}$} \\
\hline $\begin{array}{l}15-24 \\
25-34 \\
35-44 \\
45-54\end{array}$ & $\begin{array}{l}. \\
\because \\
\because\end{array}$ & $\begin{array}{l}. \\
\therefore \\
.\end{array}$ & & & & \\
\hline & Total & .. & 13 & 296 & 10 & 53 \\
\hline
\end{tabular}

296 non-hirsute patients suffered from oligomenorrhoea. The difference is highly significant $\left(\chi^{2}=28.95 ; \mathrm{P}<0.001\right)$.

Recently a small but more elaborate analysis was begun, employing a grading of hair growth over the trunk and limbs in addition to the sites already described and using somewhat less stringent criteria for the occurrence of oligomenorrhoea. The correlation between oligomenorrhoea and hirsuties is emphasized, this menstrual disturbance occurring in 6 out of 9 of hirsute patients and in only 7 out of 99 of non-hirsute patients.

The incidence of epimenorrhoea in the same group of 349 patients was also studied, but no obvious difference between hirsute and non-hirsute patients in this respect was apparent.

\section{Inheritance}

The idiopathic form of hirsuties is generally thought to be familial in nature. It was decided to investigate this point by interviewing all possible relatives of subjects below the age of the menopause with a major degree of hirsuties, the only restriction being that those interviewed should live within a reasonable distance of the hospital. Because of limitations of time it was possible to examine the relatives of only 29 propositi, and of the first-degree relatives 16 sisters and 24 mothers were seen.

Table III shows the incidence of a major degree of hirsuties at any of the three sites in the mothers, in the sisters, and in a control group. The increased incidence of

TABLE III-Incidence of Hirsuties in Relatives of Hirsute Subjects

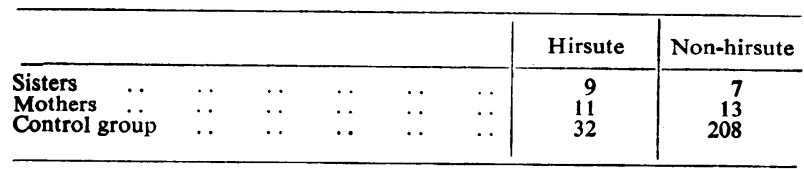

hair on the lip and chin occurring with age introduced a complicating factor; all mothers with a major degree of hirsuties on the lip and chin were therefore asked at what age the excess hair had appeared, and only when this was before the menopause was the hirsuties regarded as significant. The control group consisted of all subjects in the 1544 age group of the survey reported by Thomas and Ferriman (1957) in whom it had been possible to estimate the degree of hair growth at all three sites.
The incidence of hirsuties is clearly greater in both sisters and mothers than in the control group, and the differences are statistically significant (for the sisters $\chi^{2}=11.30, P<0.001$; for the mothers $\chi^{2}=9.95,0.01>P>0.001$ ).

Calculation of the degree of correlation between the hirsuties grading as between sisters and between daughters and mothers demonstrates that it is approximately equal for both, the value of the correlation coefficient being in the neighbourhood of 0.5 . This, taken in conjunction with the fact that hirsuties exists as a graded phenomenon, suggests that the inheritance is multifactorial.

The incidence of oligomenorrhoea in the sisters and mothers was also compared with that in the same control

TABLE IV.-Incidence of Oligomenorrhoea in Relatives of Hirsute Subjects

\begin{tabular}{|c|c|c|c|c|c|c|c|}
\hline & & & & & & Oligomenorrhoea & Total \\
\hline $\begin{array}{l}\text { Sisters } \quad . \\
\text { Mothers } \quad \ldots \\
\text { Control group }\end{array}$ & $\begin{array}{l}. . \\
\because .\end{array}$ & $\begin{array}{l}\cdots \\
\cdots\end{array}$ & $\begin{array}{l}. \\
. .\end{array}$ & $\begin{array}{l}. \\
\therefore\end{array}$ & $\begin{array}{l}. . \\
. .\end{array}$ & $\begin{array}{r}5 \\
3 \\
16\end{array}$ & $\begin{array}{r}16 \\
24 \\
240\end{array}$ \\
\hline
\end{tabular}

group. The results are given in Table IV. The incidence in both groups of relatives is higher than in the controls. The difference is definitely significant for the sisters $\left(\chi^{2}=\right.$ $8.51 ; 0.01>P>0.001)$, but does not reach the level of statistical significance for the mothers $\left(\chi^{2}=0.92\right)$.

An observation of some interest concerned the variability of the condition within members of the same family. Relatives of patients with major grades of hirsuties on the lip, chin, or lower abdomen were encountered with oligomenorrhoea but without hirsuties of this order. A more extensive assessment of hair growth involving other areas of the body might have revealed a tendency to hirsuties in these relatives. However, oligomenorrhoea probably occurs at times without gross hirsuties in the syndrome under discussion, and gross hirsuties can certainly exist with normal menstrual periodicity.

\section{Discussion}

The association of major degrees of hirsuties with increased shoulder width and a raised urinary excretion of 17-ketosteroids reported here is considered to indicate a general tendency towards masculinity in hirsute women. The recognition of a constitutional variant in women in which the deviations from the normal are in the male direction has been made several times before (for example, Kretschmer, 1936 ; Bayer, 1939), although detailed analyses have not been undertaken. Many of the differences between males and females are a matter of degree, and in this respect individuals can be regarded not so much as male or female but as masculine or feminine. The term androgyny (Draper, 1941) has been employed to refer to the presence of android features in the female and gynaecoid features in the male. This concept has been applied by Tanner (1951) for differences in body build between males and females, and is implicit in the studies on hair growth of Danforth and Trotter (1922) and Dupertuis, Atkinson, and Elftman (1945).

The term "constitutional virilism" is convenient to describe the individuals under discussion. Some 135 such patients have been under study. The condition presents features additional to those described above, and, although these have not been investigated so systematically, some comment is perhaps permissible. Oligomenorrhoea is clearly the characteristic menstrual disturbance, but epimenorrhoea and bouts of menorrhagia have also been encountered. Anovulatory cycles occur with some frequency in some of the patients, but the majority probably ovulate quite regularly. Laparotomies have been performed for various reasons on a number of these patients (only occasionally with a view to wedge resection of the ovaries) and polycystic ovaries have been observed in several. The practice of family limitation and other factors make the assessment of infertility difficult in these days. It can be stated unequivocally, however, that virilism of this character is no 
absolute bar to conception: indeed, the most hirsute patient in the series had five children. On the other hand, it does appear likely that there is a definite tendency to infertility in a certain proportion of the patients.

Enlargement of the clitoris had not been looked for systematically, but it has been observed on only two occasions, and is regarded as distinctly uncommon. It would also have been of interest to make an assessment of the degree of muscularity and subcutaneous fat development. A further aspect that merits attention is that of the personality structure of these individuals.

Barr and Bertram (1949) reported the discovery of special chromatin bodies in the nerve cells of cats, found only in female animals. These observations were extended to human skin by Moore, Graham. and Barr (1953) and later to other tissues, and it has become customary to think of the relationship as an all-or-none phenomenon. However, it is noteworthy that Davidson and Robertson Smith (1954) noted a considerable variation in the ease with which the characteristic "drumsticks" could be found in polymorphonuclear neutrophil leucocytes from female patients, the incidence ranging from 1:6 to $1: 98$. Some preliminary observations have been made on the incidence of these chromatin bodies in hirsute women, and, although the numbers as yet are few, a possible difference between hirsute and nonhirsute subjects may exist, a lesser incidence being encountered in the former. This is conceivably a further expression of a general tendency towards masculinity.

\section{Summary}

An association has been demonstrated between hirsuties and two other masculine characters in women-namely, increased shoulder width and raised 17-ketosteroid excretion. A significant correlation has also been demonstrated between hirsuties and oligomenorrhoea. The term constitutional virilism is a convenient one to describe the composite syndrome. The condition appears to be genetically determined, and the results obtained suggest that the inheritance is multifactorial.

We wish to thank all those who referred cases, and in particular Dr. Joan Chappell and Mr. K. A. K. Hudson. We thank Professor H. Grünberg, F.R.S., and Dr. J. S. Small for advice. Dr. J. F. Heggie kindly allowed us laboratory facilities. The 17-ketosteroid estimations were performed by Dr. A. B. Anderson, Dr. W. G. Dangerfield, and Mr. C. W. Hall. One of us (P. K. T.) was in receipt of a grant from the North Middlesex Hospital, which is gratefully acknowledged.

\section{REFERENCES}

Barr. M. L., and Bertram, E. G. (1949). Nature (Lond.), 163, 676 Bavet L. M. (1939). Endocrinology. 24, 260.

Danforth. C. H.. and 1roiter. M. (1922). Amer. J. phys. Anthrop., 5, 259. Davidenn, W. M., and Smith, D. R. (1954). Brit. med. J., 2, 6.

Drarer. O. (1941). New Engl. J. Med.. 225, 393.

Dubertuis. C. W., Atikinson, W. B., and Elftman, H. (1945). Hum. Biol.

Kretschmer. B. (1936). Physique and Character, 2nd ed. Kegan Paul, London.

Lindegárd. B. (1953). Acta Dsychiat. (Kbh.), Suppl. 86

Moore. K. L.. Graham, M. A., and Barr, M. L. (1953). Surg. Gynec. Obstel.. 96,641

Jkerli,. B. (1953). Bum. Blol., 25, 32

Tanner. J. M. (1951). Lancet. 1. 544.

homas, P. K., and Ferriman, D. G. (1957). Amer. J. phys. Anthrop. In

"During the last 10 years the majority of men blinded in the second world war have been settled in their homes after the hospitals had healed their wounds and St. Dunstan's had taught them how to be blind." This is stated by Sir IAN FRASER in his introduction to the 42nd annual report of St. Dunstan's, "Blindness Conquered," which covers the year ended March 31, 1957. Throughout the Commonwealth there were about 1,750 such blinded persons ; some had stayed in their own countries, where local organizations were looking after them, others had regained some sight, and a substantial number after training had gone back to Commonwealth countries.

\section{RECOVERY AFTER DEPRESSIVE ATTACK OF 30 YEARS' DURATION}

BY

\author{
G. M. WODDIS, M.R.C.S., L.R.C.P., D.P.M. \\ Physician-Superintendent and Consultant Psychiatrist. \\ The Coppice, Nottingham
}

Most authorities refer to the difficulty of making prognoses in depressive attacks. The statistical surveys of Fuller and Johnston (1931), Lundquist (1945), and Danziger (1946) all refer to the extreme variation in length of attack, but it has not been possible to find any description of a specific case of long duration in any of the literature studied.

The patient who is the subject of this article was studied in one hospital for over 20 years, for 12 years by me personally, and his history shows that he suffered from a single unbroken attack of depressive psychosis lasting at least from 1918 to 1949 , when he made a complete recovery at the age of 69 . He is still leading an active and successful life.

\section{Case Fictory}

The patient, a Church of England clergyman, was admitted to The Coppice in 1929 at the age of 49 . He was then extremely depressed, lethargic, retarded in thought. and monosyllabic in speech. He had ideas of personal unworthiness, thought God had deserted him, and his general attitude was one of hopelessness and despair.

He was the youngest child of his father's third marriage, there being 13 children in all. The father, a worrier, irritabie, strict, and demanding absolute obedience, was 68 when the patient was born, and lived to the age of 95 , working as a parson until he was $\mathbf{9 0}$. There was no family history of overt mental illness, and so far as is known no other members of the family have ever needed psychiatric treatment. As a child and at school the patient always felt he was a dud compared with his brothers, who had won open scholarships at Oxford. He was conscientious and drove himself hard, was afraid of failure, and compensated for his feelings of scholastic mediocrity by excelling at games. Apart from this over-conscientiousness there was no evidence of obsessional features in his personality.

He was intended for the study of medicine and was expected to complete his preliminary studies in one term. Hard slogging ended in failure, and he had his first attack of depressive illness then, characterized by suicidal thoughts. The next five years were spent in a mental home. but during the last three years of this period he was employed as games organizer.

His symptoms in this attack were similar to but milder than those which developed in his second major attack. He was depressed. felt that everything was no good, that he was a misery and did not deserve to live. In spite of suicidal thoughts be made no suicidal attempts, and he appears to have made a complete recovery.

At the age of 26 he entered a theological college, was ordained, joined the lndian Army, and $u$ ent to India at the age of 31. Three years later, on the outbreak of the first world war, he saw service in Mesopotamia, where he was captured by the Turks. Over two years were spent in prison camps, seeing terrible sights and undergoing privation of every sort, some self-inflicted when his sense of duty led him to make sacrifices for those of less favourable rank than himself.

On his return to England he felt that everything was an effort and that he found no pleasure in meeting people. So far as is known he had remained perfectly stable on 